\title{
Local behavior and lymph node metastases of Wilms' tumor: accuracy of computed tomography ${ }^{*}$
}

\author{
Comportamento local e metástases linfonodais do tumor de Wilms: acurácia da tomografia \\ computadorizada
}

\section{Eduardo Just da Costa e Silva ${ }^{1}$, Giselia Alves Pontes da Silva ${ }^{2}$}

Silva EIC, Silva GAP. Local behavior and lymph node metastases of Wilms' tumor: accuracy of computed tomography. Radiol Bras. 2014 Jan/Fev; 47(1):9-13.

Abstract Objective: To evaluate the accuracy of computed tomography for local and lymph node staging of Wilms' tumor.

Materials and Methods: Each case of Wilms' tumor was evaluated for the presence of abdominal lymph nodes by a radiologist. Signs of capsule and adjacent organ invasion were analyzed. Surgical and histopathological results were taken as the gold standard.

Results: Sensitivity was $100 \%$ for both mesenteric and retroperitoneal lymph nodes detection, and specificity was, respectively, $12 \%$ and $33 \%$, with positive predictive value of $8 \%$ and $11 \%$ and negative predictive value of $100 \%$. Signs of capsular invasion presented sensitivity of $87 \%$, specificity of $77 \%$, positive predictive value of $63 \%$ and negative predictive value of $93 \%$. Signs of adjacent organ invasion presented sensitivity of $100 \%$, specificity of $78 \%$, positive predictive value of $37 \%$ and negative predictive value of $100 \%$.

Conclusion: Computed tomography tumor showed low specificity and low positive predictive value in the detection of lymph node dissemination. The absence of detectable lymph nodes makes their presence unlikely, and likewise regarding the evaluation of local behavior of tumors.

Keywords: Computed tomography; Wilms' tumor; Staging.

Resu mo Objetivo: Avaliar a acurácia da tomografia computadorizada no estadiamento local e linfonodal de pacientes com tumor de Wilms.

Materiais e Métodos: Um radiologista avaliou a presença de linfonodos abdominais em cada caso. Sinais de invasão capsular e de órgão adjacente foram analisados. Resultados cirúrgicos e histopatológicos foram tomados como padrão ouro.

Resultados: A sensibilidade da detecção de linfonodos mesentéricos e retroperitoneais foi 100\% (ambos) e a especificidade foi 12\% e 33\%, respectivamente, com valores preditivos positivos de $8 \%$ e 11\% e negativos de $100 \%$ (ambos). Sinais de invasão capsular apresentaram sensibilidade de $87 \%$, especificidade de $77 \%$ e valores preditivos positivo de $63 \%$ e negativo de $93 \%$. Invasão de órgão adjacente foi diagnosticada com sensibilidade de $100 \%$, especificidade de $78 \%$ e valores preditivos positivo de $37 \%$ e negativo de $100 \%$.

Conclusão: A tomografia computadorizada mostrou baixa especificidade e valor preditivo positivo na detecção de disseminação linfonodal. Ausência de linfonodos detectáveis tornou a disseminação improvável, assim como sinais de invasão local.

Unitermos: Tomografia computadorizada; Tumor de Wilms; Estadiamento.

\section{INTRODUCTION}

Imaging diagnosis methods are essential in the assessment of abdominal neoplasms. Such methods can confirm the presence of disease, characterize the tumor, organ of origin and evaluate its behavior in relation to adjacent structures, vascular invasion, metastases and treatment response $^{(1,2)}$.

The accuracy of computed tomography (CT) in the characterization of the local extent of Wilms' tumor (WT) has

* Study developed in the Program of Post-Graduation in Child and Adolescent Health at Universidade Federal de Pernambuco (UFPE), Recife, PE, Brazil.

1. $\mathrm{PhD}, \mathrm{MD}$, Radiologist, Universidade Federal de Pernambuco (UFPE) and Instituto Materno Infantil de Pernambuco (IMIP), Recife, PE, Brazil.

2. PhD, Full Professor of Pediatrics, Maternal-Infantile Department - Universidade Federal de Pernambuco (UFPE), Recife, PE, Brazil.

Mailing Address: Dr. Eduardo Just da Costa e Silva. Avenida Boa Viagem, 4000, ap. 202, Boa Viagem. Recife, PE, Brazil, 51021-000. E-mail: eduardojust@oi.com.br.

Received July 31, 2012. Accepted after revision October 2, 2013. been brought into question ${ }^{(3)}$. Gow et al. have reported poor correlation between CT and histopathological staging ${ }^{(3)}$. In the present study, staging with CT was correct in 10 out of 26 patients (38\%). Some aspects of the study, such as the criteria utilized to define capsular integrity, can hardly be evaluated. Tumor size was evaluated into two dimensions and correlated with the size of the contralateral kidney. The relationship between capsular invasion and non-resectability as well as between tumor size and non-resectability was not evaluated.

Currently, two approaches for the initial management of WT are adopted with similar results ${ }^{(3,4)}$. Such approaches are based on studies developed by two cooperative groups, namely, National Wilms' Tumor Study (NWTS) and International Society of Paediatric Oncology (SIOP). The main difference between such studies is that the NWTS indicates initial surgical treatment for resectable tumors, followed by chemotherapy, while the SIOP proposes chemotherapy for 
all the patients. The SIOP proposal is based on the expectation that there will be a lower incidence of surgical complications. The NWTS proposal is modified for adjuvant preoperative treatment in cases where the tumor is considered non-resectable. However, it is difficult to determine the respectability of a tumor ${ }^{(3)}$.

Tumor histology and staging represent the main prognostic factors in cases of $\mathrm{WT}^{(4)}$. The tumor staging is defined by surgical and histopathological findings. The presence of enlarged abdominal lymph nodes observed at imaging studies may suggest metastatic dissemination, although parameters to determine such finding are still to be established.

The present study was aimed at evaluating computed tomography findings in patients with WT in correlation with histopathological findings in relation to the local behavior of the lesion and ganglia involvement, as well as evaluating predictive factors of intraoperative tumor rupture.

\section{MATERIALS AND METHODS}

The present study was previously approved by the Committee for Ethic in Research of the authors' institution, and the term of free and informed consent was waived.

The study sample was based on a list of all patients diagnosed with WT who underwent preoperative CT in the authors' institution.

The images were retrospectively reviewed by a pediatric radiologist with eight-year experience in the interpretation of cancer patients' images. The images were acquired with either of two apparatuses, namely, Aura (Philips Medical Systems; Best, The Netherlands) or Somatom Emotion 6 (Siemens Medical Solutions; Forchheim, Germany). In order to reduce the ionizing radiation in studies performed at the authors' unit, pre-contrast phase images are not acquired. The images were analyzed on a Carestream ${ }^{\circledR}$ workstation (Carestream Health Inc.; Rochester, USA), utilizing all the resources available in the system, such as images reformation and windows adjustment. Except for the final diagnosis of $\mathrm{WT}$, the investigator was blind to the surgical and histopathological findings.

The adopted imaging parameters are shown on Table 1.

Information such as CT equipment identification and time span between the CT study and surgery were recorded. Height, weight and age of the patients as well as tumors' stage were obtained from their clinical records.

Patients submitted to chemotherapy in the period between CT and surgery were excluded from the study. The association between intraoperative tumor rupture, tumor índex, capsular invasion and adjacent organ invasion was investigated. The following ratios were calculated: mass area/ abdominal area; mass area/body surface; largest mass diameter/body surface area; mass index/body surface area; mass index/patient's weight; and mass index/patient's height.

Central tendency measures were obtained (mean or median, according to the results distribution following normality
Table 1 -Computed tomography imaging parameters.
Bird beak sign ${ }^{(a)}$
Laterality
Calcifications
Fat
Necrosis
Necrosis degree ${ }^{(b)}$
Mass diameter. The product of the three measurements defined a variable called mass index (MI). The ratio between $\mathrm{Ml}$ and body mass index was named tumor index (TI)
Mass area and abdominal area (measured on the largest axial diameters)
Signs of capsular invasion ${ }^{(\mathrm{c})}$ and/or invasion of adjacent organ ${ }^{(\mathrm{d})}$
Identification of mesenteric and/or retroperitoneal lymph nodes, with their largest and smallest diameters ${ }^{(\mathrm{e})}$
Presence of clusters of mesenteric and retroperitoneal lymph nodes ${ }^{(f)}$
Ascites
Renal vein thrombosis
Metastasis to abdominal organs
Contralateral mass

\footnotetext{
(a) Defined as presence of a sharply-shaped deformity on the renal parenchyma a the interface with the tumor.

(b) Grade I = 0-25\% of the mass; grade II = 25-50\%; grade III = 50-75\%; grade IV $\geq 75 \%$.

(c) The capsule is considered intact in cases where the renal parenchyma is nor mal externally to the tumor border and normal attenuation of the perirenal fat.

(d) Defined by an irregular interface between the tumor and the evaluated solid organ, or parietal thickening in segments of the digestive tract. Hepatic invasion was specifically evaluated utilizing the same criterion.

(e) Always measured in the axial plane. The ratio between the two measurements defined an additional variable: diameters ratio.

${ }^{\left({ }^{(7)}\right.}$ Defined as presence of cluster of three or more lymph nodes.
}

test), with their dispersion measurements. The differences were evaluated by means of parametric or non-parametric tests, after Bartlett's test. Sensitivity, specificity, positive predictive value and negative predictive value of the findings of capsular invasion or adjacent organ invasion were calculated, taking histopathological results as gold standard. A significance level of $95 \%$ was established. The statistical analyses were performed with the software Epi-Info for Windows.

\section{RESULTS}

Twenty-six CT studies were reviewed - 50\% (13/260 acquired with multislice equipment. The patients' age ranged from six to 86 months (median $=53 ; \mathrm{Q} 1-\mathrm{Q} 3=49-66$ ); $57.7 \%(15 / 26)$ were male, and $42.3 \%$ (11/26) female individuals. A contralateral lesion was detected in $7.7 \%$ of the patients (2/26). Chemotherapy was performed in $80.8 \%$ (21/ 26) of the patients before undergoing the CT scan.

As regards staging, 62\% (16/26) were classified as stage III, 19\% (5/26) stage IV, and the others, classified as stage II or $\mathrm{V}$.

The time span between CT scan and surgery ranged between one and 11 days $($ median $=4 ; Q 1-Q 3=2-6)$.

The median of the largest tumor diameter was $9.3 \mathrm{~cm}$ $(\mathrm{Q} 1-\mathrm{Q} 3=7.0-12)$. The tumors were more frequently found at left $(16 / 26)$ than at right $(10 / 26)(p<0.05)$. 
Table 2-Local characteristics of 26 Wilms' tumors at computed tomography.

\begin{tabular}{lcc}
\hline Tomographic finding & $n$ & $\%$ \\
\hline Calcifications & 9 & 34.6 \\
Fat & 1 & 3.8 \\
Necrosis & 25 & 96.2 \\
Bird beak sign & 25 & 96.2 \\
Venous thrombosis & 1 & 3.8 \\
Metastasis to abdominal organ & 1 & 3.8 \\
Retroperitoneal lymph nodes & 18 & 69.2 \\
$\quad$ Clustered & $9 / 18$ & 50 \\
Mesenteric lymph nodes & 23 & 88.5 \\
Clustered & $26 / 26$ & 100 \\
\hline
\end{tabular}

$n=$ Total number of patients.

Table 3-Accuracy in the detection of retroperitoneal and mesenteric lymph nodes at computed tomography, taking histopathological results as golden standard for lymph node involvement.

\begin{tabular}{lcccc}
\hline & Se & Sp & PPV & NPV \\
\hline Retroperitoneal lymph nodes (visualization) & $100 \%$ & $33 \%$ & $11 \%$ & $100 \%$ \\
Clustered & $50 \%$ & $50 \%$ & $9 \%$ & $90 \%$ \\
Mesenteric lymph nodes (visualization) & $100 \%$ & $12 \%$ & $8 \%$ & $100 \%$ \\
$\quad$ Clustered & $100 \%$ & $8 \%$ & $8 \%$ & $100 \%$ \\
\hline
\end{tabular}

Se, sensitivity; Sp, specificity; PPV, predictive positive value; NPV, negative predictive value.

The local characteristics of the tumors are shown on Table 2 .

Histopathological studies demonstrated lymph node involvement in $7.7 \%$ of the patients $(2 / 26)$. Sensitivity, specificity, positive and negative predictive values in the detection of lymph nodes are shown on Table 3.

No statistically significant difference was observed between patients with and without lymph node involvement as regards largest or smallest diameters of mesenteric or retroperitoneal lymph nodes, or as regards the ratio between those diameters $(p>0.05)$.

Sensitivity, specificity, positive and negative predictive values of CT findings of capsular invasion were, respectively, $87 \%, 77 \%, 63 \%$ and $93 \%$; and for adjacent organ invasion, respectively, $100 \%, 78 \%, 37 \%$ and $100 \%$.

Intraoperative tumor rupture occurred in $23.1 \%(6 / 26)$ of the patients. No association was observed between tumor rupture and the other parameters included on Table 1.

\section{DISCUSSION}

Over the last decades, great changes have been observed in the use of imaging diagnosis methods in the investigation of pediatric abdominal neoplasms. Initially, such methods were utilized to confirm the presence of a mass, suggesting a specific diagnosis, but later they started playing a role in the therapy and surgical plannings, besides the evaluation of the treatment response ${ }^{(2,5-8)}$. Certain imaging findings such as presence of metastases or vascular invasion have contributed to the therapeutic planning. On the other hand, local staging and lymph node involvement are defined with basis on surgical and histopathological findings ${ }^{(3)}$.
In the present series, no statistically significant difference was observed in relation to the distribution per sex. The left size was most affected $(p<0.05)$. The patients' age at the moment of the CT scan was slightly higher than reported in the literature for the diagnosis of $\mathrm{WT}^{(7,9)}$. Considering that some patients underwent CT scan after chemotherapy, probably such a difference is not real, since some CT scans were performed few weeks after the diagnosis. The same is applied to the median of the largest tumor diameter, which has shown to be smaller than previously described ${ }^{(9,10)}$.

In the same way, the utilization of chemotherapy prior to CT scan in many patients may indicate that, at the diagnosis, some of the described characteristics do not necessarily correspond to those of tumors. Alterations that have been related to chemotherapy include decrease in tumor size, increase in the area of necrosis, calcifications, areas of fat and disappearance of contralateral lesions and venous thrombi ${ }^{(5,6,11,12)}$.

The logic associated with the use of complementary diagnostic methods is based on the principle that further studies must have the potential to add some relevant information to previously obtained clinical, imaging and laboratory data. For example, if a child in the usual age range for WT presents with a palpable mass and ultrasonography shows a solid tumor of renal origin, such a diagnosis prevails and, in most cases, it is improbable that CT or magnetic resonance imaging demonstrate any other finding which modify such a hypothesis. Thus, CT is applicable in cases where it can add information to modify the therapeutic planning. The WT staging is based on surgical and histopathological findings in association with imaging studies results. In the present study, most patients were classified as stage III. Considering that lymph nodes involvement was confirmed in only $7.7 \%$ of the patients, such a classification was based on other criteria such as local histopathological findings or previous chemotherapy. Thus, if one could define the local characteristics of a tumor by means of imaging studies, such a contribution would be relevant in the therapeutic planning.

In the present study, the findings indicate that the assessment of lymph nodes with CT cannot characterize metastases because of its low sensitivity and low positive predictive value, which is compatible with data reported by other studies $^{(3,5)}$. The imaging evaluation of abdominal lymph nodes is commonly performed in cases of other diseases. $\mathrm{Pa}$ rameters such as size, shape, attenuation and presence of calcifications or necrosis are utilized $^{(13)}$. Size is most commonly utilized, but such a parameter is limited because of the great variability in sizes of normal lymph nodes, superimposing on values for affected lymph nodes. On the other hand, affected lymph nodes may present with normal dimensions. Several authors have studied the normal dimensions of abdominal lymph nodes at imaging studies of adult individuals in different clinical conditions, but few studies with children are found in the literature ${ }^{(3,5)}$. A criterion that is frequently utilized to define lymph node enlargement is the 
smallest diameter $>4 \mathrm{~mm}$ (measured by means of ultrasonography) or $5 \mathrm{~mm}(\mathrm{CT})^{(14-17)}$. However, enlarged lymph nodes are found on imaging studies of asymptomatic patients, with these same values ${ }^{(14,18-20)}$.

Even so, the literature commonly reports that lymph nodes are rarely seen at $\mathrm{CT}$ of children in the usual age range for $W T^{(21)}$. Not always, the presence of large lymph nodes in neoplastic patients indicates the presence of metastasis, because they may be related to reactive hyperplasia which cannot be differentiated by means of imaging studies ${ }^{(8,21)}$. Even intraoperatively palpable lymph nodes are later histopathologically characterized as non-compromised ${ }^{(22)}$. Even at histopathological study, non-compromised lymph nodes may mimic WT, since they are affected by sinusoidal abnormalities ${ }^{(23)}$. Similarly, the absence of enlarged lymph nodes does not rule out their involvement ${ }^{(3)}$. However, in the present study, the negative predictive values were high both for detection of ganglions and for the presence of lymph node clusters, which indicates that ganglionic dissemination becomes improbable if lymph nodes are not visualized at CT. The non-visualization of lymph nodes indicated that lymph nodes were not compromised.

Gow et al. have reviewed 26 CT studies of patients with WT and have found a poor association between local tomographic staging and surgical/histopathological staging, highlighting the difficulty in defining capsular invasion and lymph node involvement ${ }^{(3)}$. The parameters utilized by such authors to define capsular invasion on images are not clearly described in their article and may not correspond to the parameters adopted in the present study, which may explain the differences in results. Low sensitivity and specificity in the definition of hepatic invasion are also reported in patients assessed after chemotherapy ${ }^{(5)}$. However, with the high negative predictive values, CT becomes an effective method to rule out invasion to adjacent organ and liver, but not to rule out capsular invasion.

The present study has limitations. The low prevalence of lymph nodes whose involvement is confirmed has contributed to reduce the positive predictive value of $\mathrm{CT}$. Although the definition of metastatic involvement of abdominal lymph nodes in cases of WT is done by means of histopathological findings, the knowledge of the behavior of such ganglions on images is relevant, particularly in the interpretation of post-treatment follow-up imaging studies. Usually, the detection of enlarged ganglions at any imaging method in a child with (an even remote) history of neoplasia generates preoccupation, anxiety for parents and expenses with further investigations. The knowledge that the presence of visible, even clustered lymph nodes, either enlarged or not, may be normal in neoplastic patients, indicates that the simple visualization of such ganglions at post-treatment follow-up would not be a considerable reason for preoccupation in asymptomatic patients. However, considering that lymph nodes may be enlarged in neoplastic patients due to a notnecessarily metastatic reactional process ${ }^{(23)}$, further investi- gations are necessary in patients undergoing post-treatment follow-up, since such a reactional component should be, in principle, absent. Another limitation is related to the evaluation of surgical reports. As the patients were operated by different surgeons, the findings description is not standardized. Terms like "firmly attached" or "attached" were not considered as synonym for "invaded", although it is possible that, at least in some cases, those terms had such meaning.

An aspect as regards the utility of CT in the evaluation of an abdominal tumor that is difficult to estimate is the preoperative visualization of the tumor by the surgeon. Many surgeons feel themselves more confident as, before a resection procedure, they can evaluate at CT or magnetic imaging the tumor relationship with local structures such as vessels, diaphragm and others which might make the surgery more difficult, independently of the criteria adopted to define the staging. Such characteristics are not measurable, which makes the determination of CT utility by quantitative studies more difficult.

\section{CONCLUSION}

The assessment of abdominal lymph nodes by CT in patients with WT has shown low specificity and positive predictive value to detect ganglionic dissemination. The absence of detectable ganglions, however, makes their presence improbable, with basis on histopathological findings, due to the high negative predictive value related to the non-visualization at computed tomography. The same is applied to the evaluation of the local behavior of tumors, with a good negative predictive value for findings of adjacent organ invasion. Capsular invasion was not well characterized by the method. Further studies evaluating the behavior of abdominal lymph nodes at post-treatment imaging follow-up are required to define the application of CT in this clinical context.

\section{REFERENCES}

1. Hörmann M, Puig S, Wandl-Vergesslich K, et al. Radiologic staging of thoracic and abdominal tumors in childhood. Radiologe. 1999;39:538-45.

2. Kaste SC, McCarville MB. Imaging pediatric abdominal tumors. Semin Roentgenol. 2008;43:50-9.

3. Gow KW, Roberts IF, Jamieson DH, et al. Local staging of Wilms' tumor - computerized tomography correlation with histological findings. J Pediatr Surg. 2000;35:677-9.

4. Kaste SC, Dome JS, Babyn PS, et al. Wilms tumour: prognostic factors, staging, therapy and late effects. Pediatr Radiol. 2008;38:2 17.

5. Ng YY, Hall-Craggs MA, Dicks-Mireaux C, et al. Wilms' tumour: pre- and post-chemotherapy CT appearances. Clin Radiol. 1991;43: 255-9.

6. Olsen ØE, Jeanes AC, Sebire NJ, et al. Changes in computed tomography features following preoperative chemotherapy for nephroblastoma: relation to histopathological classification. Eur Radiol. 2004;14:990-4.

7. Riccabona M. Imaging of renal tumours in infancy and childhood. Eur Radiol. 2003;13 Suppl 4:L116-29.

8. Brisse HJ, Smets AM, Kaste SC, et al. Imaging in unilateral Wilms tumour. Pediatr Radiol. 2008;38:18-29. 
9. Maudgil DD, McHugh K. The role of computed tomography in modern paediatric uroradiology. Eur J Radiol. 2002;43:129-38.

10. Miniati D, Gay AN, Parks KV, et al. Imaging accuracy and incidence of Wilms' and non-Wilms' renal tumors in children. J Pediatr Surg. 2008;43:1301-7.

11. Refaie HD, Sarhan M, Hafez A. Role of CT in assessment of unresectable Wilms' tumor response after preoperative chemotherapy in pediatrics. ScientificWorldJournal. 2008;8:661-9.

12. Jeanes AC, Beese RC, McHugh K, et al. Fatty degeneration in a Wilms' tumour after chemotherapy. Eur Radiol. 2002;12 Suppl 3: S149-51.

13. McMahon CJ, Rofsky NM, Pedrosa I. Lymphatic metastases from pelvic tumors: anatomic classification, characterization, and staging. Radiology. 2010;254:31-46.

14. Vignault F, Filiatrault D, Brandt ML, et al. Acute appendicitis in children: evaluation with US. Radiology. 1990;176:501-4.

15. Karmazyn B, Werner EA, Rejaie B, et al. Mesenteric lymph nodes in children: what is normal? Pediatr Radiol. 2005;35:774-7.

16. Simanovsky N, Hiller N. Importance of sonographic detection of enlarged abdominal lymph nodes in children. J Ultrasound Med. 2007;26:581-4.
17. Watanabe M, Ishii E, Hirowatari Y, et al. Evaluation of abdominal lymphadenopathy in children by ultrasonography. Pediatr Radiol. 1997;27:860-4.

18. Ying M, Ahuja A, Brook F. Sonographic appearances of cervical lymph nodes: variations by age and sex. J Clin Ultrasound. 2002;30: $1-11$.

19. Rao PM, Rhea JT, Novelline RA. CT diagnosis of mesenteric adenitis. Radiology. 1997;202:145-9.

20. Vassallo P, Wernecke K, Roos N, et al. Differentiation of benign from malignant superficial lymphadenopathy: the role of highresolution US. Radiology. 1992;183:215-20.

21. Siegel MJ, Chung EM. Wilms' tumor and other pediatric renal masses. Magn Reson Imaging Clin N Am. 2008;16:479-97, vi.

22. Othersen HB Jr, DeLorimer A, Hrabovsky E, et al. Surgical evaluation of lymph node metastases in Wilms' tumor. J Pediatr Surg. 1990;25:330-1.

23. Weeks DA, Beckwith JB, Mierau GW. Benign nodal lesions mimicking metastases from pediatric renal neoplasms: a report of the National Wilms' Tumor Study Pathology Center. Hum Pathol. 1990;21:1239-44. 